\title{
Title: Whither Robotic Colorectal Surgery?
}

Authors:

Julie Flynn, MBBS, FRACS*

Department of Surgery, Epworth Healthcare, Richmond

Division of Cancer Surgery, Peter MacCallum Cancer Centre

Jose T. Larach, MD, MSChCP

Division of Cancer Surgery, Peter MacCallum Cancer Centre

Satish Warrier, MBBS, FRACS

Department of Colorectal Surgery, Alfred health

Alexander Heriot, MD, FRACS

Division of Cancer Surgery, Peter MacCallum Cancer Centre

${ }^{*}$ Corresponding author:

Julie Flynn

Department of Surgery, Epworth Healthcare, Bridge Rd, Richmond, 3121

Jafly1@gmail.com

+61470415567

Disclosures:

J Flynn No conflicts

T Larach Educational grant funded by Intuitive Surgical

This is the author manuscript accepted for publication and has undergone full peer review but has not been through the copyediting, typesetting, pagination and proofreading process, which may lead to differences between this version and the Version of Record. Please cite this article as doi: 10.1111/ans.16067

This article is protected by copyright. All rights reserved. 
S Warrier Honorarium for proctoring robotic cases

A Heriot No conflicts

This article is protected by copyright. All rights reserved. 


\section{Whither Robotic Colorectal surgery?}

Robotic colorectal surgery remains controversial. With outcomes similar to laparoscopy, the costs are seen as prohibitive by many. Yet the achievement of equal outcomes so early in its evolution promises greater benefits to come, for patients as well as surgeons due to better ergonomics. Costs, meanwhile, should reduce as technology advances and alternative robotic platforms enter the market, pushing more competitive pricing.

Robotic-assisted surgery using the da Vinci@ surgical system (Intuitive Surgical, CA, USA) has been widely adopted in Australia since its introduction in 2003 (1). As the technology has evolved, its applications have moved well beyond its original roots in urology, into other surgical specialties.

The NSW Ministry of Health and the Victorian Department of Health and Human Services (DHHS) commissioned a review of robotic-assisted surgery in 2018 (2). The report concluded that 'robot-assisted surgery is safe and effective' but there is 'little or no difference in outcomes.'

The subsequent DHHS policy position (3) states that the costs of the robotic platform 'do not appear to be offset by benefits to patients or savings to the health system'. Therefore, DHHS 'does not support further adoption of robot-assisted surgery but recommends ongoing use of existing robots within an evaluation framework' and recommends 'further development of training and credentialing standards.'

This may induce a sense of déjà vu for some. In the 1990's, laparoscopy sparked similar debate. The first laparoscopic cholecystectomy in Australia took six hours (4). As surgeons 
gained experience with the new technique, increased bile duct7 injuries were reported (5). Referrals to biliary units increased and longer operative times reduced the number of cases performed (5). A 1990 report commented on increased costs and lack of evidence for clinical benefits (6). Sound familiar?

Most studies comparing robotic to laparoscopic colorectal surgery have found equal outcomes in terms of resection margins, adequate TME, lymphadenectomy and complication rates. Some studies have found benefits in recovery and long-term function after robotic surgery $(7,8)$. The first large randomised controlled trial comparing robotic to laparoscopic rectal surgery, the ROLARR trial (7) found no difference in overall conversion rates. However, subgroup analysis showed lower conversion rates in males, obese patients and low tumours. This may reflect greater benefits of a robotic assisted approach with more complex surgery. Outside of clinical trials, surgeons are more likely to attempt and complete more complex colorectal work with a robotic platform compared with a laparoscopic approach (9).

The surgeons in the ROLARR trial had, on average, performed more than double the number of laparoscopic rectal resections than robotic. They had extensive laparoscopic colorectal experience, yet unlike early laparoscopic surgeons, they achieved equivalent outcomes very early in their robotic experience. Further investment into laparoscopy led to more refined techniques and better equipment. The same evolution is already occurring in robotic surgery.

Conversely, it should be remembered that a technology dependent platform mandates close relationships between industry and clinicians. Potential bias and conflict of interest must be a consideration when interpreting study results, with evidence showing poor declaration of 
conflicts by authors (10) and correlation between industry funding and findings in favour of robotic surgery (11). Oversight is essential.

Robotic surgery is also much kinder to the surgeon. Sixty-eight percent of surgeons report generalised pain (12), with minimally invasive surgeons at far greater risk of pain, fatigue and numbness. Musculoskeletal symptoms are linked to reduced performance, burnout and earlier retirement (13).

Lower physical symptom rates are reported in robotic surgery (14). When performing identical simulator tasks laparoscopically and robotically, surgeons showed significant reductions in both cognitive and physical stress parameters as well as improved performance using the robot (15). Surgeons endure physical discomfort and injury to give their patients the best possible treatment, however can this be minimised?

Robotic surgery has particular benefits for training, allowing closer supervision and more precise mentor engagement. A procedure can be undertaken on a simulator first and then using a dual console, with direct input and control by the instructor, collecting real time training data for further analysis.

Early in its evolution, robotic colorectal surgery has already proven safe, with at least equal results to laparoscopy. New robotic platforms are likely to increase the uptake and application of robotics and reduce costs and operative time. Patient and surgeon focused evaluation and assessment is essential to ensure safety and benefit, however continuing to invest in the robotic field should be seen as a worthy investment in the future of surgery.

This article is protected by copyright. All rights reserved. 


\section{References:}

1. Weber PA, Merola S, Wasielewski A, Ballantyne GH. Telerobotic-assisted laparoscopic right and sigmoid colectomies for benign disease. Diseases of the Colon \& Rectum. 2002;45(12):1689-94; discussion 95-6.

2. Review of robot-assisted surgery.

NSW Ministry of Health. Victoria Department of Health and Human Services. 2018.

3. Victorian Department of Health and Human Services- Robot assisted surgery Policy Position Statement August 2019. 2019.

4. Hardy KJ. Laparoscopic cholecystectomy: Australian beginnings. ANZ J Surg. 2011;81(12):866-70.

5. $\quad$ Fletcher DR. The introduction of laparoscopic cholecystectomy to Australia and New Zealand: an illustration of establishing training and standards for new clinical privileges. Ambulatory Surgery. 1994;2:86-90.

6. Hirsch NA. AlHW laparoscopic-cholecystectomy Discussion paper. Health Technology Unit, Australian Institute of Health. 1990.

7. Jayne D, Pigazzi A, Marshall H, Croft J, Corrigan N, Copeland J, et al. Robotic-assisted surgery compared with laparoscopic resection surgery for rectal cancer: the ROLARR RCT Efficacy and Mechanism Evaluation. 2019;6(10).

8. Wang G, Wang Z, Jiang Z, Liu J, Zhao J, Li J. Male urinary and sexual function after robotic pelvic autonomic nerve-preserving surgery for rectal cancer. Int J Med Robot. 2017;13(1).

9. Narasimhan V, Das A, Waters P, McCormick J, Heriot A, Warrier S. Complete mesocolic excision and central vascular ligation for right-sided cancers: is it time to jump on board? ANZ J Surg. 2020;90(1-2):11-2.

10. Patel SV, Yu D, Elsolh B, Goldacre BM, Nash GM. Assessment of Conflicts of Interest in Robotic Surgical Studies: Validating Author's Declarations With the Open Payments Database. Ann Surg. 2018;268(1):86-92.

11. Criss CN, MacEachern MP, Matusko N, Dimick JB, Maggard-Gibbons M, Gadepalli SK. The Impact of Corporate Payments on Robotic Surgery Research: A Systematic Review. Ann Surg. 2019;269(3):389-96.

12. Stucky CH, Cromwell KD, Voss RK, Chiang YJ, Woodman K, Lee JE, et al. Surgeon symptoms, strain, and selections: Systematic review and meta-analysis of surgical ergonomics. Ann Med Surg (Lond). 2018;27:1-8.

13. Davila VJ, Meltzer AJ, Hallbeck MS, Stone WM, Money SR. Physical discomfort, professional satisfaction, and burnout in vascular surgeons. J Vasc Surg. 2019;70(3):913-20 e2.

14. Lee MR, Lee GI. Does a robotic surgery approach offer optimal ergonomics to gynecologic surgeons?: a comprehensive ergonomics survey study in gynecologic robotic surgery. J Gynecol Oncol. 2017;28(5):e70.

15. van der Schatte Olivier RH, Van't Hullenaar CD, Ruurda JP, Broeders IA. Ergonomics, user comfort, and performance in standard and robot-assisted laparoscopic surgery. Surg Endosc. 2009;23(6):1365-71. 


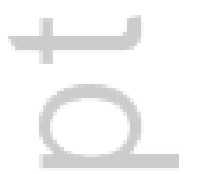

4 


\section{University Library}

\section{- M M I E R R A A gateway to Melbourne's research publications}

Minerva Access is the Institutional Repository of The University of Melbourne

Author/s:

Flynn, J;Larach, JT;Warrier, S;Heriot, A

Title:

Whither robotic colorectal surgery?

Date:

2020-07-01

Citation:

Flynn, J., Larach, J. T., Warrier, S. \& Heriot, A. (2020). Whither robotic colorectal surgery?. ANZ JOURNAL OF SURGERY, 90 (7-8), pp.1230-1232. https://doi.org/10.1111/ans.16067.

Persistent Link:

http://hdl.handle.net/11343/275968 